\title{
Analysis of the Private University Teachers' Sub-health Status and \\ Preventive Measures
}

\author{
Jie-Li \\ Zhengzhou University of Industrial Technology, 451100, Henan, China
}

Keywords: private university teacherssub-health prevention measures

\begin{abstract}
Private colleges foundation weak, relatively frequent, full-time teachers in private colleges teachers this relatively special group, and it has become the mainstream of health, but its performance is different from the rest of the population, fatigue is the common symptom of private college teachers. Private colleges, society, education department, the teacher should make joint efforts to actively respond to and improve the quality of private college teachers' life, promoting the sustainable development of private colleges.
\end{abstract}

\section{Introduction}

Inferior health, is the body in a physical structure degradation and function is of poor quality and psychological imbalance, to a large extent is the incubation period of chronic diseases. At present, the society of private colleges teachers pay close attention to health. In recent years, the group of intellectuals in the non-governmental university faculty, especially middle-aged teachers has become the mainstream of sub health crowd. Run by the local university teachers' heavy incidence of sub-health is as high as $54.16 \%$. Non-governmental university faculty of sub-health condition has already become an urgent need to solve the problem.

\section{Mainly sub-health state}

Sub-health state of the main form of physical, psychological and social adaptation and moral four sorts of change. The particularity of university teachers in their professional performance is different from the rest of the population. According to the survey: $70.29 \%$ of the teachers have different degrees of sore throat, $80.15 \%$ of the teachers feel neck pain, $79.23 \%$ of the teachers feel back pain and lower limb numbness, pain, etc.A symptom of fatigue is a widespread feeling university teachers, this also is the typical symptom of sub-health state.

\section{The causes of sub-health}

Work pressures. With the reform of higher education, private colleges scale expands unceasingly, more and more people into the private colleges teachers group. But between private colleges for more students and better development, the competition is intense, the competition between universities outstanding performance in the teacher education, teaching, scientific research ability put forward higher, more strict requirements, now many private colleges are electives this kind of teaching mode, in order not to be eliminated, forced the young teacher had to spend lots of time and effort to improve education to make up and the experience of the gap between the old teacher. The development of science and technology in the college teachers' teaching method, role, 
and teaching quality put forward higher requirements. Outside the bear heavy teaching task, more stress from school workload evaluation indicators, workload and undertake research projects for teachers teaching in colleges and universities the number of published papers have specific requirements. According to the survey, college teachers working hours a day on average at about 11 hours, $68 \%$ of people feel work pressure big, with $22 \%$ of people even think that "huge" pressure. Published papers and apply for scientific research subject pressure makes the young teachers working overtime, sleep time is not enough. Survey showed that $42.9 \%$ of the teachers' rest $10-12$ o 'clock at night, there are $21.6 \%$ of the teachers to rest after 12 o 'clock in the evening, there are $54.4 \%$ of the teachers often work on weekends. Middle-aged teachers is the salt of the earth, the school backbone, family support. Much as the leader, under research, and professional title promotion, children education, family burden of pressure, etc. Male itself pressure in today's society, family, society, academic status, personal development, economic status, etc.) is larger than female, male teachers' sub-health status was higher than that of female teachers, that is consistent with the results of the survey. Long-term working overtime, overdraw physical strength and energy to work, have worked and sleepless nights is true portraiture of middle-aged teachers' life. Eventually lead to physical health. With the booming of young and middle-aged intellectuals in colleges and universities, their health is all the liabilities and final berth at the point of the life. Medical experts believe that these young teachers encountered two transformation, social transformation and transformation of the body. Make them anxious social transformation, transformation of the body to let them sick. If not value and to overcome these problems, they could drop at any time. China's "untimely death" tragedy most occurred in aged 45 to 55 middle-aged intellectuals. Long-term stress and stress causes the body's physiological function changes, sympathetic, parasympathetic nerve balance is destroyed, the sympathetic nervous excitement, increased calamine in the blood, the heart rate increase fast, cardiac oxygen consumption increase, will cause or aggravate cardiovascular disease. Long-term tired, unable to get timely relief resulting in a decline in immune function and the ability to resist disease, increase the chance of malignant tumor and infection. Engineering physics, Songhua university professor Welshmanago heavyweight scholars because of lung carcinoma, missed the best treatment timing and died.

Psychological pressure. University teachers' psychological stress is the main to work pressure, the current policy of science and technology to the young and middle-aged intellectual task too much pressure, evaluation system and the related polarization distribution system, forcing the rivalry between the young and middle-aged intellectuals close to cruelty. Competition, evaluation of the title, the bottom out, on the paper must be SCI, EI paper retrieval, children education and so on make the competition between teachers, teachers under the unprecedented pressure, plus some teachers expect too much of yourself, desire for success, virtually increased the pressure for yourself. At the same time, the evaluation of professional titles, housing, some unreasonable phenomena in the promotion and application for scientific research topic are more likely to affect the young and middle-aged teachers. To produce psychological problems. Anxiety, main show is fear, panic. Mood easily excited, when things get angry easily, wonks, too care about others to your evaluation. Because of private higher institutions lack of psychological counseling for students, the lack of corresponding aid teachers similar department. Plus teachers are busy working, communication face is too narrow, or the lack of appropriate communication skills, because in the face of some teachers don't want to turn to professional doctor. Teachers' psychological pressure can not get effective guidance. Over time, can make the person depressed, pressure and can lead to neurasthenia, neurosis, the occurrence of diseases such as headache, high blood pressure and recurrence. 
Lifestyle. With the economic development, living standards improve, the traditional diet structure change, increased intake of fat and carbohydrates. Vitamin intake is reduced, resulting in weight gain, and the corresponding causes fatty liver, hypertension, hyperglycemia, are at increased risk of CHD, and solution is education of inhuman university 1087 senior intellectuals health analysis showed that the ratio of hyperglycemia was 38.3\%. Hypertension was $30.7 \%$, increased blood glucose/diabetes abnormal egg was 15.4\% 29.3\%. Some college teachers' heavy smoking, drinking, medical research shows that smoking the body prone to vessel spasm, organs lead to local blood supply, nutrients and oxygen supply is reduced, especially in the respiratory tract mucous is not supply of oxygen and nutrients, disease-resistant ability drops. Alcohol can cut the body's immune function. Cardiovascular disease risk increases. Lifestyle is equal to chronic diseases, in particular, some irritable, competitive, and typical type A personality features of men, research shows that now the age of the patients with cardiovascular diseases is becoming more and more tend to be younger. Before the world health organization director-general Dr Island macro points out that "not many people died from disease, but died of ignorance, died in an unhealthy way of life".

\section{Preventive measures of sub-health status}

Social and school management departments should give full attention. In the sub-health state of private college teachers is a serious potential danger, will influence the construction of teachers, affect the sustainable development of private colleges. Become the important factors that affect the quality of higher education. Related functional departments should give teachers create a relatively loose and harmonious working and living conditions. Improve teachers' health, stable teacher troop, to promote the further development of the colleges and universities.

Intensify publicity and education. Strengthen the consciousness of health survey showed that nearly $50 \%$ of college teachers do not know the concept of sub-health. Through publicity and education teachers understand the sub-health, know the dangers of it and how to effectively control. Sub-health state is not terrible, through active intervention can be turned to health. Through the publicity column, special lectures on the health knowledge, newspaper, campus network and so on various forms to introduce teachers to the health care knowledge. Especially the campus network can make up for time, place, manpower, material resources limited, interactive. To promote teachers to establish a good lifestyle and health habits. Lead teachers to positive attitude into positive behavior.

\section{Conclusion}

Sub-health is a state of dangerous threat to health of body and mind, to test by means of modern medicine in time, so that as soon as possible to understand the status of the individual body, early disease intervention, no matter for personal rehabilitation, still has the effect of get twice the result with half the effort, economically get comprehensive physical examination for teachers on a regular basis and to establish health files. Protecting teachers' health. Firstly, should be a happy and healthy people. Cherish health, cherish life, to value education more. How to effective prevention and control of the university teachers' sub-health status is deserving of further study of teachers. 


\section{References}

[1]. Julie, christoffel Chung, cu-in fan, etc., the young teachers in colleges and universities and the health risk factor Logistic regression analysis [J]. Journal of public health of China, 2003, 12 (5) : 595-596

[1]. Xiaopingu, Li ping, Ding Beige, colleges and universities of young and middle-aged people of sub-health state the results of the survey and analysis [J]. Journal of navy general hospital, 2005, 17 (5) : 183-184 